RESEARCH ARTICLE

\title{
Postischemic administration of Sendai virus vector carrying neurotrophic factor genes prevents delayed neuronal death in gerbils
}

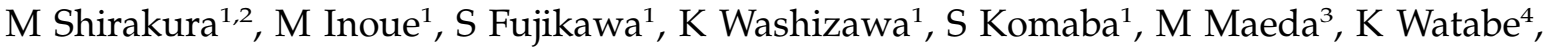 \\ Y Yoshikawa ${ }^{2}$ and $M$ Hasegawa ${ }^{1}$ \\ ${ }^{1}$ DNAVEC Research Inc., Tsukuba, Japan; ${ }^{2}$ Department of Biomedical Science, Graduate School of Agricultural and Life Sciences, \\ University of Tokyo, Tokyo, Japan; ${ }^{3}$ First Department of Anatomy, Osaka City University Medical School, Osaka, Japan; and \\ ${ }^{4}$ Department of Molecular Neuropathology, Tokyo Metropolitan Institute for Neuroscience, Tokyo, Japan
}

\begin{abstract}
Sendai virus (SeV) vector-mediated gene delivery of glial cell line-derived neurotrophic factor (GDNF) and nerve growth factor (NGF) prevented the delayed neuronal death induced by transient global ischemia in gerbils, even when the vector was administered several hours after ischemia. Intraventricular administration of SeV vector directed high-level expression of the vector-encoded neurotrophic factor genes, which are potent candidates for the treatment of neurodegenerative diseases. After occlusion of the bilateral carotid arteries of gerbils, SeV vector carrying GDNF (SeV/GDNF), NGF (SeV/NGF), brain-derived neurotrophic factor (SeV/ $B D N F)$, insulin-like growth factor-1 (SeV/IGF-1) or vascular endothelial growth factor (SeV/VEGF) was injected into the
\end{abstract}

lateral ventricle. Administration of SeV/GDNF, SeV/NGF or SeV/BDNF $30 \mathrm{~min}$ after the ischemic insult effectively prevented the delayed neuronal death of the hippocampal CA1 pyramidal neurons. Furthermore, the administration of $\mathrm{SeV} / \mathrm{GDNF}$ or SeV/NGF as late as 4 or $6 \mathrm{~h}$ after the ischemic insult also prevented the death of these neurons. These results indicate that SeV vector-mediated gene transfer of neurotrophic factors has high therapeutic potency for preventing the delayed neuronal death induced by transient global ischemia, and provides an approach for gene therapy of stroke.

Gene Therapy (2004) 11, 784-790. doi:10.1038/sj.gt.3302224

Published online 12 February 2004

Keywords: Sendai virus; cerebral ischemia; delayed neuronal death; GDNF; NGF

Neurons are postmitotic and highly differentiated, and are extremely vulnerable to ischemic injury. Pyramidal cells of the hippocampal CA1 region are well known to be especially vulnerable to cerebral ischemia. ${ }^{1,2}$ Neuronal cell death in the CA1 region itself is not death-dealing but results in severe deficits of memory function. ${ }^{3-5}$ Since the regeneration of neuronal cells remains critically difficult at present, protection against the neuronal loss induced by ischemic injury is vital in cerebrovascular-type dementia.

Glial cell line-derived neurotrophic factor (GDNF) is a potent neurotrophic factor that promotes the cell survival and differentiation of dopaminergic neurons ${ }^{6,7}$ and motoneurons. 8,9 Nerve growth factor (NGF) also has a potent ability to protect neurons from various injuries and promote the survival of cholinergic neurons. ${ }^{10-12}$ These neurotrophic factors may be valuable as candidates for use in therapy of neurodegenerative diseases. It has been reported that the neuronal cell death induced by ischemic injury was prevented by the administration of $\mathrm{GDNF}^{13-15}$ and $\mathrm{NGF}^{16-18}$ proteins. However, the usefulness of such protein factors in patients is limited because of their poor bioavailability and short half-lives.

Correspondence: M Inoue, 1-25-11 Kannondai, Tsukuba-shi, Ibaraki 3050856, Japan

Received 16 May 2003; accepted 29 November 2003; published online 12 February 2004
Moreover, these agents might be ineffective without direct injection and continuous infusion into the ventricle, striatum or cerebral cortex. Therefore, virus vectormediated gene transfer is expected to be an effective approach for the delivery of therapeutic proteins into the central nervous system (CNS). Even in the case of unsustained, but transient, expression by the vectors, it would enable significant cutting down of the number of required administrations. Previous studies demonstrated that gene transfer of neurotrophic factors such as GDNF $^{19}$ and NGF $^{20,21}$ rescued neuronal cells from ischemic injury in animal models. However, there have not been any reports in which neurotrophic factors expressed using conventional vectors such as adenovirus, retrovirus or adeno-associated virus were shown to promote the survival of neurons when the vectors were administered after ischemia.

We have developed a new type of gene transfer vector using Sendai virus ( $\mathrm{SeV})$, which is classified as a type I parainfluenza virus belonging to the family Paramyxoviridae with a negative-strand RNA genome. ${ }^{22,23}$ $\mathrm{SeV}$ has a strictly cytoplasmic life cycle in mammalian cells, that is, its genomic RNA is restricted to the cytoplasm and has no interaction with the host chromosomes. ${ }^{22}$ Therefore, SeV vector causes no genotoxicity such as the permanent integration in the target cells sometimes observed with other conventional viral 
vectors. SeV has the ability to infect most mammalian cells such as neuronal and muscular cells and directs high-level gene expression in these cells. ${ }^{23-26}$ Indeed, we observed potent infectivity of $\mathrm{SeV}$ vector in ependymal cells after intraventricular administration in the CNS. ${ }^{27}$ When the SeV vector carrying enhanced green fluorescent protein gene ( $\mathrm{SeV} / \mathrm{GFP}$ ) was administered into the left lateral ventricle of gerbils, intense GFP expression was observed around the ependymal layer of the lateral ventricles (Figure 1c) and around the hippocampus (Figure 1b). Immunohistochemical analysis using antiSeV antibody clearly showed that the cells supporting $\mathrm{SeV}$ replication were ependymal cells in the lateral ventricles (Figure 1d), third ventricle (Figure 1e) and around the hippocampus (Figure 1f). We previously showed that $\mathrm{SeV}$ vector-mediated gene transfer of GDNF 4 days before transient ischemia prevented the delayed neuronal death induced by transient global ischemia in gerbils. ${ }^{27}$ However, $\mathrm{SeV}$ vector was administered prior to the ischemic insult in that case, too, whereas gene therapy must be applied after the occurrence of a stroke for clinical application. In the present study, we examined the effects of postischemic administration of $\mathrm{SeV}$ vectors carrying GDNF, NGF and other neurotrophic factor genes on the delayed neuronal death induced by transient global ischemia. Our results suggest that $\mathrm{SeV}$ vector-mediated gene transfer has a therapeutic high potential for cerebral ischemia.
In order to confirm the efficient gene transfer and expression of $\mathrm{SeV}$ in the CNS, the proteins derived from the genes harbored in the $\mathrm{SeV}$ vector were quantified. $\mathrm{SeV}$ vectors such as $\mathrm{SeV} / \mathrm{GDNF}, \mathrm{SeV} / \mathrm{NGF}$ and $\mathrm{SeV} /$ GFP were administered into the left lateral ventricle of gerbils at $5 \times 10^{6} \mathrm{PFU} /$ head, and the amount of GDNF and NGF proteins in the hippocampus was quantified by ELISA assays. High-level expression of GDNF (114 $\pm 6 \mathrm{pg} / \mathrm{mg}$ tissue) and NGF $(1130 \pm 60 \mathrm{pg} / \mathrm{mg}$ tissue $)$ proteins was detected in the hippocampus of gerbils as early as 1 day after injection of SeV/GDNF and SeV/ NGF, respectively (Figure $2 \mathrm{a}, \mathrm{b}$ ). In contrast, only a very small amount of GDNF or NGF protein was detected when the gerbils were treated with SeV/GFP. The expression of GDNF $(2340 \pm 200 \mathrm{pg} / \mathrm{mg}$ tissue $)$ and NGF (3360 $\pm 290 \mathrm{pg} / \mathrm{mg}$ tissue) proteins reached peak levels 4 days after injection of SeV/GDNF and SeV/NGF, respectively, and then returned to the original level 14 days after the injection. In another experiment, an increment of GDNF expression in the cerebrospinal fluid was detected $8 \mathrm{~h}$ after injection of SeV/GDNF (data not shown). These results indicate that rapid and high-level expression of neurotrophic factors can be achieved by the administration of $\mathrm{SeV}$ vectors in the CNS. Also, the expression level achieved using $\mathrm{SeV}$ vectors was remarkably high compared with that achieved using adenovirus. For example, the GDNF concentration was reported to be $2.2 \pm 0.5 \mathrm{pg} / \mathrm{mg}$ tissue 1 day after the
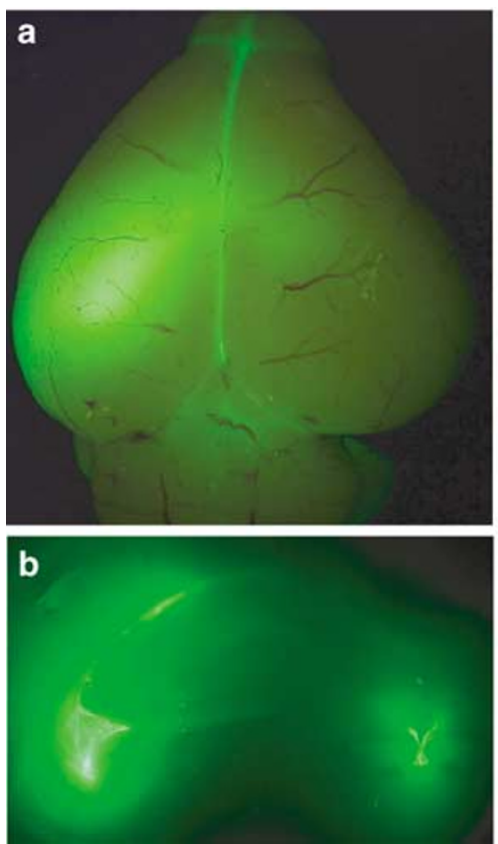
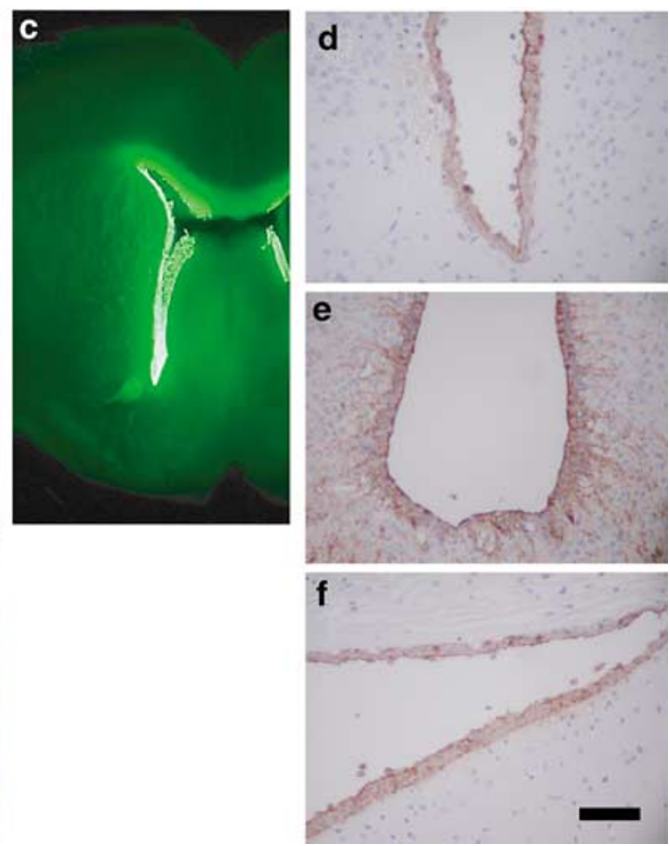

Figure 1 Identification of cell types supporting SeV replication. SeV vector carrying GFP gene (SeV/GFP; $5 \times 10^{6}$ PFU/head) was injected into the left lateral ventricle of gerbils as described previously, ${ }^{27}$ and the GFP expression 4 days after the injection was observed under a stereoscopic fluorescence microscope (Leica, Germany) from the surface of the top of brain (a) and with coronal sections around the hippocampus (b) and lateral ventricle (c). For the coronal sections, the brain was sliced into 300-4m-thick slices with a microslicer (DTK-1000; Dosaka, Japan). Representative photographs of immunohistochemical staining for SeV are shown (d-f). The paraffin sections were pretreated with $0.3 \% \mathrm{H}_{2} \mathrm{O}_{2}$ in PBS, followed by washing thrice. After blocking with $10 \%$ normal goat serum (NGS) in PBS for $1 \mathrm{~h}$, the sections were incubated overnight at $4^{\circ} \mathrm{C}$ with a rabbit polyclonal antibody to SeV (anti$\mathrm{SeV})^{28}$ in 3\% NGS and 0.3\% Triton X-100 in PBS. The sections were then washed and incubated for $1 \mathrm{~h}$ with biotinylated anti-rabbit IgG (Vector Laboratories, Burlingame, CA, USA), followed by incubation for $1 \mathrm{~h}$ with the reagents for avidin-biotin complex formation (Vector Laboratories). Immunopositive cells were visualized by reaction with 3,3'-diaminobenzidine tetrahydrochloride (DAB) (WAKO Pure Chmicals, Tokyo, Japan) and counterstained with hematoxylin. Scale bars $=100 \mu \mathrm{m}$. The ependymal cells along the (d) lateral ventricle, $(e)$ third ventricle and (f) hippocampus were SeV positive. 
injection into the cortex of adenovirus $\left(1 \times 10^{8} \mathrm{PFU} /\right.$ head) carrying the GDNF gene. ${ }^{29}$

We next examined the effects of the postischemic administration of $\mathrm{SeV}$ vectors on the delayed neuronal death of the hippocampal CA1 pyramidal cells induced by transient ischemia. It has been reported that the direct administration of the bcl-2 gene mediated by adenoassociated virus (AAV) into pyramidal neurons within $1 \mathrm{~h}$ after ischemic insult prevents the delayed neuronal death in gerbils. ${ }^{30}$ However, direct injection of virus vectors into the cerebral parenchyma cells, especially in
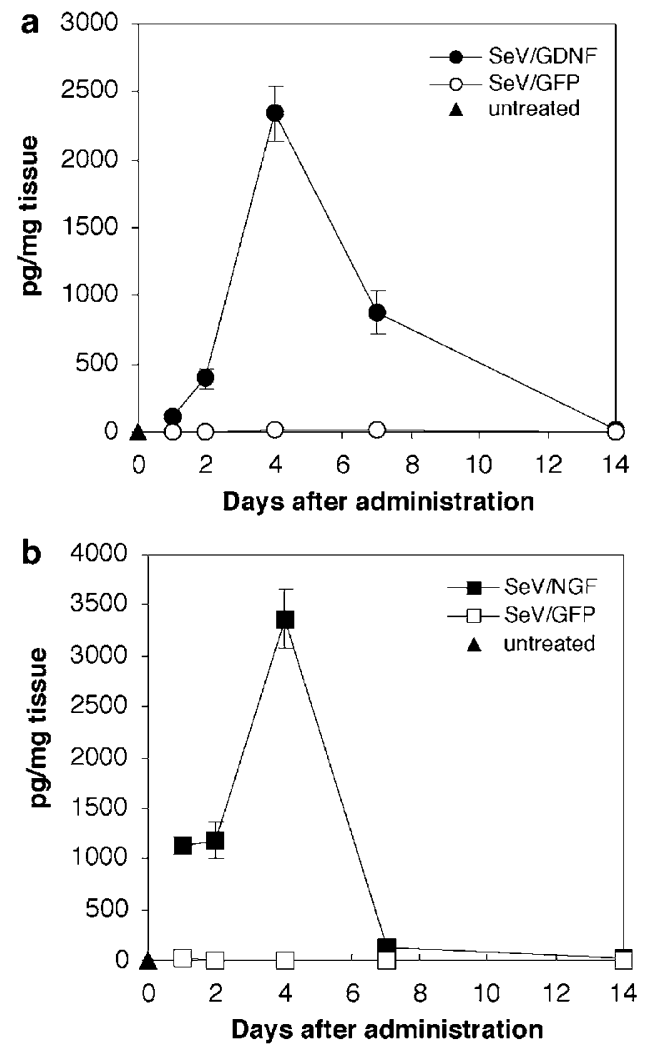

Figure 2 Kinetics of the expression of GDNF and NGF proteins in the hippocampus. Gerbils were injected with $\mathrm{SeV}$ vectors carrying GDNF (SeV/GDNF), NGF (SeV/NGF) or GFP (SeV/GFP) genes $\left(5 \times 10^{6} \mathrm{PFU} /\right.$ head, $\mathrm{n}=20$ animals per group) into the left lateral ventricle as described. ${ }^{27}$ At 1, 2, 4, 7 or 14 days after the injection, the concentrations of GDNF and NGF in the hippocampus were measured using ELISA kits (Promega, WI, USA) as previously described. ${ }^{27}$ The hippocampus was harvested from four gerbils at each time point. SeV/GDNF and SeV/GFP were constructed as previously described. ${ }^{27} \mathrm{SeV} / \mathrm{NGF}$ was constructed as described..$^{27,28}$ Briefly, mouse NGF (accession number: M14805) cDNA was amplified with a pair of NotI-tagged (underlined) primers containing $\mathrm{SeV}$-specific transcriptional regulatory signal sequences, $5^{\prime}$-ACTTG CGGCCGCCAAAGTTCAGTAATGTCCATGTTGTTCTACACTCTG-3' and 5'-ATCCGCGGCCGCGATGAACTTTCACCCTAAGTTTTTCTTA CTACGGTCAGCCTCTTCTTGTAGCCTTCCTGC-3'. The amplified fragment was introduced into the NotI site of the parental pSeV18 ${ }^{+} b(+)$, $+)$, which was constructed to produce the exact SeV full-length antigenomic RNA, to generate $p S e V / N G F$. $p S e V / N G F$ was transfected into LLC-MK $K_{2}$ cells after infection of the cells with vaccinia virus vTF7-3, which expresses $T 7$ polymerase. The T7-driven full-length recombinant SeV/NGF RNA genomes were encapsulated by NP, $P$ and L proteins, which were derived from the respective cotransfected plasmids. After incubation for $40 \mathrm{~h}$, cell lysates of transfected cells were injected into embryonated chicken eggs to amplify the recovered viruses. The virus titers were determined using a hemagglutination units (HAU) assay. Values are expressed as the mean \pm s.d. the hippocampus, is more invasive than intraventricular administration. Therefore, we selected a single intraventricular administration and utilized SeV-transduced ependymal cells to produce proteins from the genes carried by the vectors. ${ }^{27}$ Accordingly, SeV/GDNF and $\mathrm{SeV} / \mathrm{NGF}\left(5 \times 10^{6} \mathrm{PFU} /\right.$ head $)$ were injected into the lateral ventricles of ischemic gerbils after $30 \mathrm{~min}$ of occlusion of the bilateral carotid arteries, and histopathological analysis was conducted 6 days after the injection. The effects of the above vectors were compared with those of $\mathrm{SeV}$ vectors carrying brain-derived neurotrophic factor (SeV/BDNF), insulin-like growth factor-1 (SeV/ IGF-1) and vascular endothelial growth factor (SeV/ VEGF). All the genes carried by the vectors have been reported to prevent neuronal degeneration after transient ischemia, ${ }^{31-33}$ and for each $\mathrm{SeV}$ vector, vector-derived expression in infected cells was confirmed in vitro (data not shown). In sham-operated gerbils, surviving wheellike nuclei were observed in the pyramidal cells in CA1 (Figure 3a). However, in gerbils treated with SeV/GFP, almost all of the pyramidal cells in the hippocampal CA1 region showed pyknotic degenerative nuclei in the pyramidal cells (Figure $3 \mathrm{~g}$ ). In contrast, treatment of gerbils with $\mathrm{SeV} / \mathrm{GDNF}$ or $\mathrm{SeV} / \mathrm{NGF}$ ameliorated the delayed neuronal death in the hippocampal CA1 pyramidal cells (Figure $3 b, c)$. Treatment with $\mathrm{SeV} /$ BDNF also showed ameliorative effects (Figure $3 d$ ), but treatment with SeV/VEGF did not (Figure 3f). Treatment with SeV/IGF-1 showed ameliorative effects (Figure 3e) in only two gerbils among eight tested. For quantitative analysis, the number of surviving neurons/1-mm length in the hippocampal CA1 region was counted (Figure 4). Treatment with SeV/GDNF $(180.8 \pm 11.7$ cells $/ \mathrm{mm})$ or $\mathrm{SeV} / \mathrm{NGF} \quad(142.4 \pm 24.3$ cells $/ \mathrm{mm})$ significantly prevented neuronal death as compared to treatment with $\mathrm{SeV} / \mathrm{GFP}(10.7 \pm 1.9$ cells $/ \mathrm{mm})(P<0.01)$. Treatment with $\mathrm{SeV} / \mathrm{BDNF}(139.3 \pm 29.7$ cells $/ \mathrm{mm})$ also reduced the cell death of the neurons by about $70 \%$. SeV/GDNF and $\mathrm{SeV} / \mathrm{NGF}$ (and SeV/BDNF) proved to be better for the treatment of transient global ischemia than $\mathrm{SeV}$ vectors carrying genes for the other factors investigated here. As a way to confirm that the vector-derived growth factors actually increased and acted to prevent the neuronal death of the hippocampal CA1 pyramidal neurons, we measured the concentrations of both NGF and GDNF proteins in the hippocampus of 'ischemic' gerbils 4 days after the injection of $\mathrm{SeV} / \mathrm{GDNF}$ or $\mathrm{SeV} / \mathrm{NGF}$ into the lateral ventricle. When the $\mathrm{SeV} / \mathrm{GDNF}$ was injected at $4 \mathrm{~h}$ after ishemia, the concentration of GDNF $(71.9 \pm 12.0 \mathrm{pg} / \mathrm{mg}$ tissue) was increased compared to that of SeV/GFP-injected $(0.057 \pm 0.022 \mathrm{~g} / \mathrm{mg}$ tissue $)$ or untreated $(0.038 \pm 0.042 \mathrm{pg} / \mathrm{mg}$ tissue $)$ gerbils. However, the concentration of NGF $(15.8 \pm 0.9 \mathrm{pg} / \mathrm{mg}$ tissue) remained at the original level of $\mathrm{SeV} / \mathrm{GFP}$-injected $(15.4 \pm 4.6 \mathrm{pg} / \mathrm{mg}$ tissue) or untreated $(18.2 \pm 6.2 \mathrm{pg} / \mathrm{mg}$ tissue) gerbils. When the $\mathrm{SeV} / \mathrm{NGF}$ was injected at $4 \mathrm{~h}$ after ischemia, the concentration of NGF $(1570 \pm 210 \mathrm{pg} /$ $\mathrm{mg}$ tissue) but not that of GDNF $(0.074 \pm 0.047 \mathrm{pg} / \mathrm{mg}$ tissue) increased, and this NGF could show a neuroprotective effect. These results indicate that the vectorderived growth factors rather than the intrinsic ones increase and function to prevent the neuronal death.

To examine the effect of extending the time until the administration of $\mathrm{SeV}$ vectors after ischemic insult, which is important for practical use in clinical applications, 
$\mathrm{SeV} / \mathrm{GDNF}$ and SeV/NGF were injected $4 \mathrm{~h}$ after ischemia. Surviving neurons in the hippocampal CA1 region were observed in gerbils treated with either $\mathrm{SeV} /$ GDNF or SeV/NGF, although a few degenerated nuclei of neurons were observed in these cases (Figure 5b, c). The number of surviving neurons in the hippocampal CA1 region was also counted (Figure 6). Administration of $\mathrm{SeV} / \mathrm{GDNF}(114.7 \pm 9.7$ cells $/ \mathrm{mm})$ or $\mathrm{SeV} / \mathrm{NGF}$ $(127.6 \pm 13.8$ cells $/ \mathrm{mm})$ prevented the neuronal death as compared to administration of SeV/GFP ( $14.3 \pm 5.6$ cells / $\mathrm{mm})(P<0.01)$, even if the vectors were administered $4 \mathrm{~h}$ after ischemia. Moreover, treatment with $\mathrm{SeV} / \mathrm{GDNF}$ $(74.2 \pm 9.6$ cells $/ \mathrm{mm})$ or $\mathrm{SeV} / \mathrm{NGF}(76.4 \pm 10.8$ cells $/ \mathrm{mm})$ $6 \mathrm{~h}$ after ischemic insult was also effective for prevention of the delayed neuronal death as compared to treatment with SeV/GFP $(11.7 \pm 2.3$ cells $/ \mathrm{mm})(P<0.01)$ (Figure 5e, $f$ and Figure 6). Equal neuroprotective effects were observed on the ipsilateral and contralateral sides of the hippocampal CA1 region (data not shown), indicating that the proteins expressed by $\mathrm{SeV}$ vectors were extensively dispersed. These results indicate that administration of $\mathrm{SeV} / \mathrm{GDNF}$ or $\mathrm{SeV} / \mathrm{NGF}$ even several hours after ischemia effectively prevents the delayed neuronal death induced by transient global ischemia. There have been no previous reports showing that the administration of virus vector-mediated genes at $4 \mathrm{~h}$ or even $6 \mathrm{~h}$ after an ischemic insult was effective for preventing the delayed neuronal death induced by transient ischemia in animal models. Our results indicate that the time window for the treatment of cerebral ischemia could be substantially extended. It was reported that more than $8 \mathrm{~h}$ was required for the expression of genes carried by adenovirus vectors in the rat brain. ${ }^{34}$ Thus, the time needed for expression of genes carried by $\mathrm{SeV}$ vector may be shorter than that needed for genes carried by adenovirus vector. The rapid gene expression achieved using $\mathrm{SeV}$ vectors may be due to the rapid replication, high level of mRNA transcription and effective translation of the mRNA of the vectors, that is, the typical features of RNA viruses. This may have led to the protective effect observed even with $6 \mathrm{~h}$ postischemic administration of $\mathrm{SeV}$ vectors against the delayed

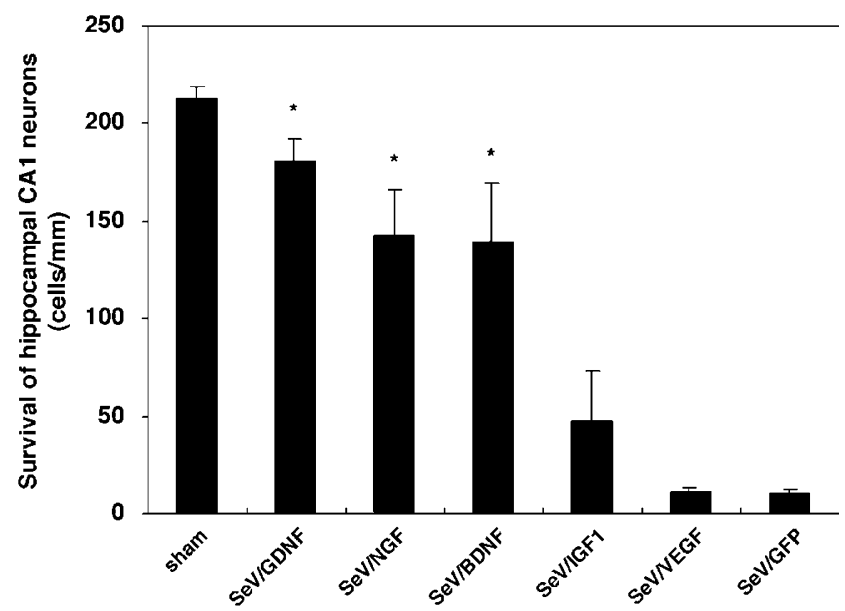

Figure 4 Quantitative analysis of the effect of $\mathrm{SeV}$ vector on ischemic injury when administered $30 \mathrm{~min}$ after ischemia. SeV/GDNF, SeV/NGF, SeV/BDNF, SeV/IGF-1, SeV/VEGF or SeV/GFP was injected intraventricularly 30 min after ischemic insult. The number of surviving neurons/ 1-mm length in the hippocampal CA1 region was calculated. Values are expressed as the mean \pm s.d. $(n=8$ animals per group $)$. Asterisks indicate a significant difference as compared with the SeV/GFP-treated group. $(P<0.01$, Student's t test $)$.
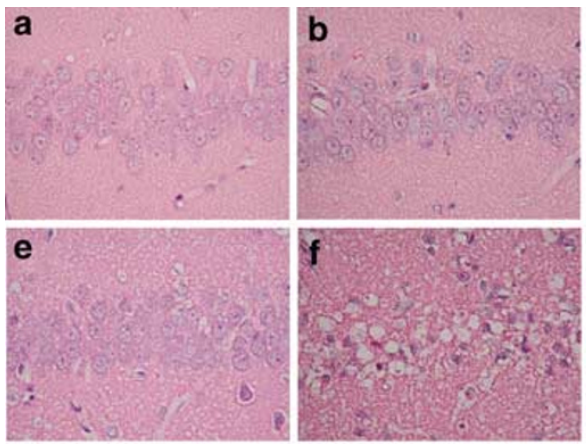
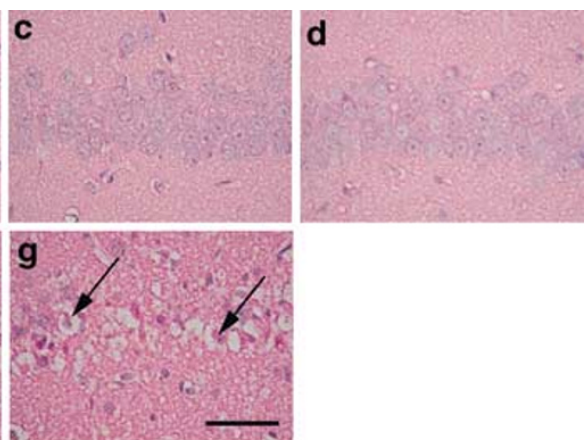

Figure 3 Representative photographs of pyramidal neurons in the hippocampal CA1 region after treatment (30 min after ischemia) with SeV vector following ischemic injury. (a) Sham-operated gerbils; (b) SeV/GDNF-, (c) SeV/NGF- (d) SeV/BDNF-, (e) SeV/IGF-1-, (f) SeV/VEGF- and (g) SeV/GFPtreated gerbils 30 min after ischemic insult. These sections were stained with hematoxylin and eosin. Arrows indicate the pyknotic nuclei of neurons. Scale bar $=50 \mu \mathrm{m}$. SeV vectors carrying the BDNF (SeV/BDNF), IGF-1 (SeV/IGF-1) and VEGF (SeV/VEGF) genes were constructed as described in Figure 1. In this experiment, human BDNF (accession number: XM_006027), human IGF-1 (accession number: X56773) and human VEGF (accession number: AY047581) cDNAs were amplified with a pair of NotI-tagged (underlined) primers containing SeV-specific transcriptional regulatory signal sequences, $5^{\prime}$ ACTTGCGGCCGCCAAAGTTCAGTGATGACCATCCTTTTCCTTAC-3' and 5'-ATCCGCGGCCGCGATGAACTTTCACCCTAAGTTTTTCTTAC TACGGCTATCTTCCCCTTTTAATGGTCAATGTAC-3' for BDNF, 5'-ACTTGCGGCCGCCAAAGTTCAGCAATGGGAAAAATCAGCAGTCTTC-3' and 5'-ATCCGCGGCCGCGATGAACTTTCACCCTAAGTTTTTCTTACTACGGCTACATCCTGTAGTTCTTGTTTCCTGC-3' for IGF-1 and 5'ACTTGCGGCCGCCAAAGTTCACTAATGAACTTTCTGCTGTCTTGGGTGC-3' and ${ }^{\prime}$-ATCCGCGGCCGCGATGAACTTTCACCC TAAGTTTTTCTTACTACGGTCACCGCCTCGGCTTGTCACATCTGC-3' for VEGF. Adult male Mongolian gerbils (60-80 g) were used in this experiment. Occlusion of the bilateral common carotid arteries was performed as previously described. ${ }^{19,27}$ Briefly, gerbils were anesthetized by an intraperitoneal injection of chloral hydrate $(300 \mathrm{mg} / \mathrm{kg})^{19}$ and both common carotid arteries were clamped for 5 min with surgical clips to produce transient forebrain ischemia. The body temperature was measured using a thermocouple probe inserted into the anus and maintained at $37.5^{\circ} \mathrm{C}$ using a heating pad. Sham-operated animals were treated in the same manner except for occlusion of the bilateral common carotid arteries. At 30 min after the ischemic insults, $\mathrm{SeV} / G D N F, \mathrm{SeV} / \mathrm{NGF}, \mathrm{SeV} / \mathrm{BDNF}$, SeV/IGF-1, SeV/VEGF or SeV/GFP $\left(5 \times 10^{6} \mathrm{PFU} / \mathrm{head}, n=8\right.$ animals per group $)$ was injected intraventricularly into gerbils. At 6 days after injection, the gerbils were anesthetized with ether and transcardially perfused with normal saline followed by $4 \%$ paraformaldehyde in $0.1 \mathrm{M}$ phosphate buffer (PB). The brains were removed and fixed in the same fixative overnight and then processed into paraffin blocks. Coronal brain sections were cut at 5- $\mu m$ thickness and stained with hematoxylin and eosin. Arrows indicate the pyknotic nuclei of neurons. Scale bar $=50 \mu m$. 

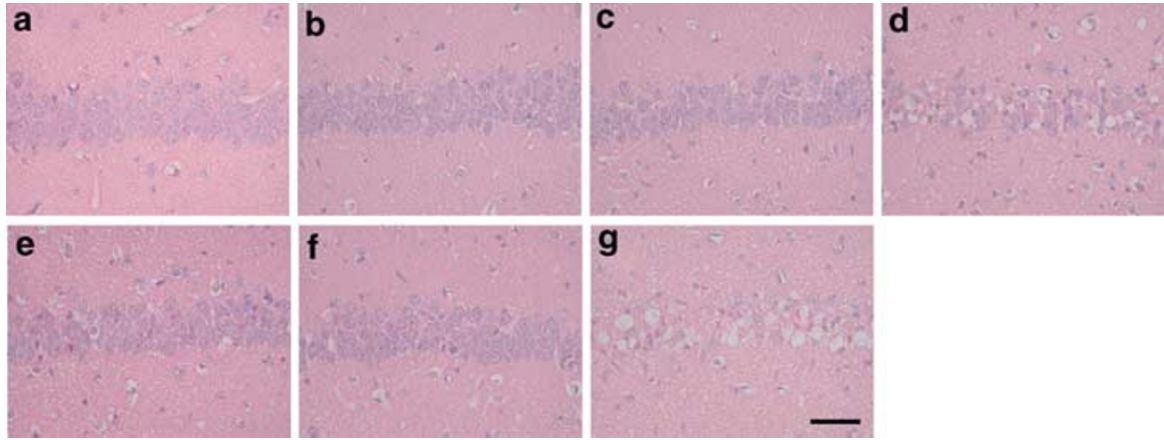

Figure 5 Representative photographs of pyramidal neurons in the hippocampal CA1 regions after treatment (4 and $6 \mathrm{~h}$ after ischemia) with SeV vector following ischemic injury. SeV/GDNF (b, e), SeV/NGF $(c, f)$ or SeV/GFP $(d, g)$ was administered intraventricularly $4 h(b, c, d)$ or $6 h(e, f, g)$ after ischemic insult. The sections were stained with hematoxylin and eosin. Scale bar $=50 \mu \mathrm{m}$. Occlusion of the bilateral common carotid arteries was performed as described in Figure 2.

neuronal death of the hippocampal CA1 pyramidal neurons induced by transient ischemia. Moreover, these attractive features of $\mathrm{SeV}$ vectors may make them useful for the treatment of acute diseases such as cerebral ischemia.

It has been reported that NGF administration prevented the delayed neuronal death when neurons were observed 7 days after ischemic insult, but not when they were observed 28 days after the insult. ${ }^{18}$ The long-term effects of the vectors studied here therefore had to be examined to better clarify their potential benefits in clinical use. Therefore, we also examined the long-term effects of $\mathrm{SeV} / \mathrm{GDNF}$ and $\mathrm{SeV} / \mathrm{NGF}$ on delayed neuronal death. The effect of $\mathrm{SeV}$ vectors for preventing neuronal death could be observed even when analyzed 28 days after the insult, although it was not seen in the case of topical application of NGF protein. ${ }^{18}$ However, the number of surviving neurons at 28 days after the ischemia was reduced to almost half of that at 6 days after ischemia in the cases of gerbils treated with $\mathrm{SeV} /$ GDNF and SeV/NGF (Figure 7). High-level expression of the vector-encoded protein was detected after the administration of the $\mathrm{SeV}$ vector, but this expression reached a peak 4 days after the administration and then decreased to the basal level by 14 days. It is probable that immune responses induced by the virus particles or genes derived from $\mathrm{SeV}$ may cause the rapid decline of the gene expression of SeV. However, this limitation may be circumvented by the development of a new generation of $\mathrm{SeV}$ vectors that elicit weaker immune responses, which should extend the duration of gene expression. We have developed a series of an attenuated type of $\mathrm{SeV}$ vectors that are $\mathrm{F}$ gene-deleted, ${ }^{24} \mathrm{~F}$ gene-deleted with preferable mutations, ${ }^{35} \mathrm{M}$ gene-deleted, ${ }^{36}$ or have combinations of deletions of these genes (Kitazato K, unpublished; Inoue $\mathrm{M}$, unpublished). We plan the first clinical application of $\mathrm{SeV}$ vector carrying human fibroblast growth factor-2 for the treatment of peripheral arterial disease using $\mathrm{F}$ gene-deleted $\mathrm{SeV}$ vector. As the $\mathrm{F}$ gene-deleted $\mathrm{SeV}$ is nontransmissible and shows less cytopathic effect than the wild-type $\mathrm{SeV}$, we should utilize this type of $\mathrm{SeV}$ (or further advanced types of $\mathrm{SeV}$ vector) for applications to brain ischemia. Improvement of the vector modifications will ultimately provide better protection against ischemic injury. Moreover, alternative administration routes, such as lumbar puncture of the vectors, should be developed for the purposes of human

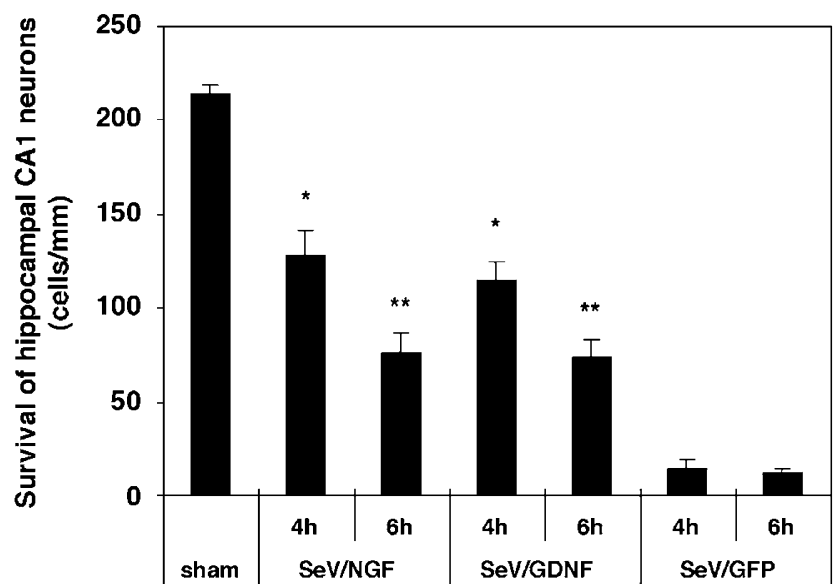

Figure 6 Quantitative analysis of the effect of $\mathrm{SeV}$ vector on ischemic injury when administered 4 and $6 \mathrm{~h}$ after ischemia. SeV/GDNF, SeV/NGF or SeV/GFP was injected intraventricularly 4 or $6 \mathrm{~h}$ after ischemic insult. The number of surviving neurons/1-mm length in the hippocampal CA1 region was calculated. Values are expressed as the mean \pm s.d. $(n=8$ animals per group). Asterisks indicate a significant difference as compared with the SeV/GFP-treated group. $(P<0.01$, Student's $t$ test $)$.

gene therapy for cerebrovascular diseases. Hayashi and co-workers ${ }^{37}$ reported that liposome-mediated hepatocyte growth factor (HGF) gene transfer into the subarachnoid space prevented delayed neuronal death in gerbils. Intrathecal injection into the cisterna magna involves no systematic anesthesia, no burr hole and no pain for patients. For use in clinical application, these methods should be tested in future studies. More importantly, we have already confirmed the efficient replication of $\mathrm{SeV}$ vectors in primates. In fact, high-level expression of GDNF (more than $100 \mathrm{ng} / \mathrm{ml}$ ) was observed in cerebrospinal fluid after the injection of $\mathrm{SeV}$ vector carrying the GDNF gene (SeV/GDNF) into the lateral ventricle of primates (data not shown). Thus, we are going to evaluate the $\mathrm{SeV} / \mathrm{GDNF}$ vector for its effects on the recovery from brain ischemia using primates. In such experiments, we hope to show a correlation between CA1 neuroprotection and functional recovery.

In conclusion, the present study demonstrated that postischemic administration of $\mathrm{SeV}$ vectors carrying genes for GDNF and NGF effectively prevented the delayed neuronal death of the hippocampal CA1 


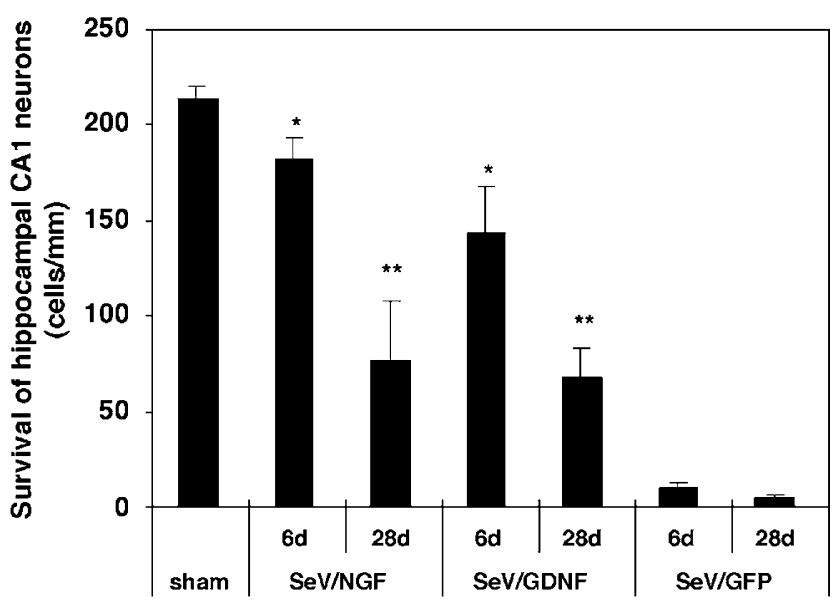

Figure 7 Long-term effect of the SeV vectors on ischemic injury. SeV/ GDNF, SeV/NGF or SeV/GFP was injected intraventricularly 30 min after ischemic insult. At 6 days or 28 days after injection, gerbils were anesthetized, and the number of surviving neurons/1-mm length in the hippocampal CA1 region was calculated. Values are expressed as the mean \pm s.d. $(n=8$ animals per group $)$. Asterisks indicate a significant difference as compared with the SeV/GFP-treated group. $(P<0.01$, Student's $t$ test).

pyramidal cells induced by occlusion of the bilateral carotid arteries. It is noteworthy that the neuroprotective effect was obtained even 4 and $6 \mathrm{~h}$ after ischemic insults. These results indicate that gene therapy using $\mathrm{SeV}$ vectors is of great potential usefulness for the treatment of cerebral ischemia.

\section{Acknowledgements}

We thank $\mathrm{T}$ Yamamoto for technical assistance, and A Iida, M Okayama and M Fukumura for helpful discussions.

\section{References}

1 Kirino T. Delayed neuronal death in the gerbil hippocampus following ischemia. Brain Res 1982; 239: 57-59.

2 Kirino T, Sano K. Selective vulnerability in the gerbil hippocampus following transient ischemia. Acta Neuropathol (Berl.) 1984; 62: 201-208.

3 Andersen MB, Sams-Dodd F. Impairment of working memory in the T-maze after transient global cerebral ischemia in the Mongolian gerbil. Behav Brain Res 1998; 91: 15-22.

$4 \mathrm{Li} \mathrm{AJ}$ et al. Protective effect of acidic fibroblast growth factor against ischemia-induced learning and memory deficits in two tasks in gerbils. Physiol Behav 1999; 66: 577-583.

5 Catania MA et al. Erythropoietin prevents cognition impairment induced by transient brain ischemia in gerbils. Eur J Pharmacol 2002; 437: 147-150.

6 Beck KD et al. Mesencephalic dopaminergic neurons protected by GDNF from axotomy-induced degeneration in the adult brain. Nature 1995; 373: 339-341.

7 Choi-Lundberg DL et al. Dopaminergic neurons protected from degeneration by GDNF gene therapy. Science 1997; 275: 838-841.

8 Henderson CE et al. GDNF: a potent survival factor for motoneurons present in peripheral nerve and muscle. Science 1994; 266: 1062-1064.
9 Li L et al. Rescue of adult mouse motoneurons from injuryinduced cell death by glial cell line-derived neurotrophic factor. Proc Natl Acad Sci USA 1995; 92: 9771-9775.

10 Fischer $\mathrm{W}$ et al. Amelioration of cholinergic neuron atrophy and spatial memory impairment in aged rats by nerve growth factor. Nature 1987; 329: 65-68.

11 Montero CN, Hefti F. Rescue of lesioned septal cholinergic neurons by nerve growth factor: specificity and requirement for chronic treatment. J Neurosci 1988; 8: 2986-2999.

12 Tuszynski MH, U HS, Amaral DG, Gage FH. Nerve growth factor infusion in the primate brain reduces lesion-induced cholinergic neuronal degeneration. I Neurosci 1990; 10: 3604-3614.

13 Abe K, Hayashi T, Itoyama Y. Amelioration of brain edema by topical application of glial cell line-derived neurotrophic factor in reperfused rat brain. Neurosci Lett 1997; 231: 37-40.

14 Kitagawa $\mathrm{H}$ et al. Reduction of ischemic brain injury by topical application of glial cell line-derived neurotrophic factor after permanent middle cerebral artery occlusion in rats. Stroke 1998; 29: $1417-1422$.

15 Miyazaki $\mathrm{H}$ et al. Glial cell line-derived neurotrophic factor protects against delayed neuronal death after transient forebrain ischemia in rats. Neuroscience 1999; 89: 643-647.

16 Shigeno $\mathrm{T}$ et al. Amelioration of delayed neuronal death in the hippocampus by nerve growth factor. J Neurosci 1991; 11: 2914-2919.

17 Yamamoto $\mathrm{S}$ et al. Protective effect of NGF atelocollagen minipellet on the hippocampal delayed neuronal death in gerbils. Neurosci Lett 1992; 141: 161-165.

18 Ishimaru $\mathrm{H}$ et al. NGF delays rather than prevents the cholinergic terminal damage and delayed neuronal death in the hippocampus after ischemia. Brain Res 1998; 789: 194-200.

19 Yagi T et al. Rescue of ischemic brain injury by adenoviral gene transfer of glial cell line-derived neurotrophic factor after transient global ischemia in gerbils. Brain Res 2000; 885: 273-282.

20 Hermann DM et al. Adenovirus-mediated GDNF and CNTF pretreatment protects against striatal injury following transient middle cerebral artery occlusion in mice. Neurobiol Dis 2001; 8: 655-666.

21 Andsberg G et al. Neuropathological and behavioral consequences of adeno-associated viral vector-mediated continuous intrastriatal neurotrophin delivery in a focal ischemia model in rats. Neurobiol Dis 2002; 9: 187-204.

22 Lamb RA, Kolakofsky D. Paramyxoviridae: the virus and their replication. In: Fields BN, Knipe DM, Howley PM (eds) Fields Virology. Lippincott-Raven: Philadelphia, 1996, pp. 1177-1204.

23 Nagai Y, Kato A. Paramyxovirus reverses genetics is coming of age. Microbiol Immunol 1999; 43: 613-624.

$24 \mathrm{Li} \mathrm{HO}$ et al. A cytoplasmic RNA vector derived from nontransmissible Sendai virus with efficient gene transfer and expression. J Virol 2000; 74: 6564-6569.

25 Yonemitsu Y et al. Efficient gene transfer to airway epithelium using recombinant Sendai virus. Nat Biotechnol 2000; 18: 970-973.

26 Shiotani A et al. Skeletal muscle regeneration after insulin-like growth factor I gene transfer by recombinant Sendai virus vector. Gene Therapy 2001; 8: 1043-1050.

27 Shirakura $\mathrm{M}$ et al. Sendai virus vector-mediated gene transfer of glial cell line-derived neurotrophic factor prevents delayed neuronal death after transient global ischemia in gerbils. Exp Anim 2003; 52: 119-127.

28 Kato A et al. Initiation of Sendai virus multiplication from transfected cDNA or RNA with negative or positive sense. Genes Cells 1996; 1: 569-579.

29 Kitagawa $\mathrm{H}$ et al. Adenovirus-mediated gene transfer of glial cell line-derived neurotrophic factor prevents ischemic brain injury after transient middle cerebral artery occlusion in rats. J Cereb Blood Flow Metab 1999; 19: 1336-1344. 
30 Shimazaki K et al. Adeno-associated virus vector-mediated bcl-2 gene transfer into post-ischemic gerbil brain in vivo: prospects for gene therapy of ischemia-induced neuronal death. Gene Therapy 2000; 7: 1244-1249.

31 Beck T et al. Brain-derived neurotrophic factor protects against ischemic cell damage in rat hippocampus. J Cereb Blood Flow Metab 1994; 14: 689-692.

32 Wang JM et al. Reduction of ischemic brain injury by topical application of insulin-like growth factor-I after transient middle cerebral artery occlusion in rats. Brain Res 2000; 859: 381-385.

33 Croll SD, Wiegand SJ. Vascular growth factors in cerebral ischemia. Mol Neurobiol 2001; 23: 121-135.
34 Abe $\mathrm{K}$ et al. In vivo adenovirus-mediated gene transfer and the expression in ischemic and reperfused rat brain. Brain Res 1997; 763: 191-201.

35 Inoue $\mathrm{M}$ et al. Non-transmissible virus-like particle formation by F-deficient Sendai virus is temperature-sensitive and reduced by mutations in M and HN proteins. J Virol 2003; 77: 3238-3246.

36 Inoue $\mathrm{M}$ et al. A new Sendai virus vector deficient in the matrix gene does not form virus particles and shows extensive cell-tocell spreading. J Virol 2003; 77: 6419-6429.

37 Hayashi $\mathrm{K}$ et al. Gene therapy for preventing neuronal death using hepatocyte growth factor: in vivo gene transfer of HGF to subarachnoid space prevents delayed neuronal death in gerbil hippocampal CA1 neurons. Gene Therapy 2001; 8: 1167-1173. 